\title{
An economic and low-carbon day-ahead Pareto-optimal scheduling for wind farm integrated power systems with demand response
}

\author{
Rui MA (凹), Kai LI, Xuan LI, Zeyu QIN
}

\begin{abstract}
Demand response (DR) and wind power are beneficial to low-carbon electricity to deal with energy and environmental problems. However, the uncertain wind power generation (WG) which has anti-peaking characteristic would be hard to exert its ability in carbon reduction. This paper introduces DR into traditional unit commitment (UC) strategy and proposes a multi-objective day-ahead optimal scheduling model for wind farm integrated power systems, since incentive-based DR can accommodate excess wind power and can be used as a source of system spinning reserve to alleviate generation side reserve pressure during both peak and valley load periods. Firstly, net load curve is obtained by forecasting load and wind power output. Then, considering the behavior of DR, a day-ahead optimal dispatching scheme is proposed with objectives of minimum generating cost and carbon emission. Non-dominated sorting genetic algorithm-II (NSGA-II) and satisfaction-maximizing method are adopted to solve the multi-objective model with Pareto fronts and eclectic decision obtained. Finally, a case study is carried out to demonstrate that the approach can achieve economic and environmental aims and DR can help to accommodate the wind power.
\end{abstract}

Keywords Low-carbon electricity, Unit commitment (UC), Day-ahead scheduling, Multi-objective optimization, Demand response (DR), Non-dominated sorting genetic algorithm-II (NSGA-II) algorithm

CrossCheck date: 8 December 2014

Received: 13 October 2014 / Accepted: 26 December 2014 / Published online: 27 February 2015

(c) The Author(s) 2015. This article is published with open access at Springerlink.com

R. MA, K. LI, X. LI, Z. QIN, Hunan Key Laboratory of Smart Grids Operation and Control, Changsha University of Science \& Technology, Changsha 410114, China

$(\bowtie)$ e-mail: marui818@126.com

\section{Introduction}

Greenhouse effect restricts human's sustainable development, and as the leading cause, carbon emission problem is drawn much attention all over the world $[1,2]$. China is now one of the biggest entities of carbon emission owing to its current situation of energy structure and generation technology. Low-carbon energy scheduling is a practical and effective way to accomplish collaborative optimization of economic and environmental protection [3, 4], and the related research is fruitful [5-7]. In [8], a math model of lowcarbon power dispatching was established by using electricity and $\mathrm{CO}_{2}$ emission data as decision variables. The study considered interaction between electricity generation and $\mathrm{CO}_{2}$ emission when the dispatch is decided to keep the balance of them. A later study addressed the problem of optimal model constructing for power systems with carbon capture power plant (CCPP), with the objectives of minimum generation and carbon emission cost [9].

Wind power, characterized by its pollution-free superiority, has become one of the most prominent renewable energy to cope with the emission problem [10]. A research in [11] constructed a double-objective optimal scheduling model including generation cost and carbon emission in wind-penetrated networks and solved it by improving particle swarm optimization algorithm. Reference [12] introduced "energy-environmental efficiency" to modify the optimal dispatch when modeling for the wind power integrated system. It is noted that, influenced by the wind profile, daily output of the wind power is uncertain and sometimes may present anti-peaking characteristic [13]. So high wind power penetration in the power system could cause pressures on peak-valley regulation and accommodating problems [14].

Smart grid has endowed the demand side with greater elasticity which is considerable enough to have demand 
response (DR) make a role in the operation of electric power systems [15-18]. For the power system, DR could be seen as a pollution-free resource just like the wind power [8], and the introduction of DR can reduce carbon emission [19]. Besides, researches show that DR can work as an absorber of the wind power at the same time [20].

Optimal scheduling considering these changes has captured much attention. In [21, 22], a generation scheduling model considering user side interaction was established, but it only took the minimum cost as a single objective, paying no attention to carbon emission. Reference [23] took wind power generation (WG) and DR into account when building a UC model, but likewise, it mainly focused on their uncertainties instead of the low-carbon effect. Reference [24] considered the traditional thermal power unit and a variety of low carbon resources of demand side together with objectives of minimum cost and carbon emission, putting the double objectives into single via fuzzy method. Reference [25] took the same objectives and also put them into single, creatively by taking carbon emission intensity as a weight coefficient, and in addition, there existed the discussion about DR ability of accommodating wind power. Multi-objective Pareto front is not obtained either in [24] or [25].

This paper proposes a multi-objective day-ahead optimal scheduling model of a wind power integrated power system with DR. Firstly, the traditional day-ahead load and output of the wind farm are analyzed, paying attention to the anti-peaking characteristic of the wind power. Secondly, DR is elaborated in detail and a way to depict is given. On the basis of that, a scheduling model with minimum carbon emission and total generation cost as objectives is established, taking DR compensation costs and reserve constraints into account. Thirdly, a solving process based on the non-dominated sorting genetic algorithm-II (NSGA-II) and satisfaction-maximizing method is designed, which could provide the optimal Pareto front and the optimal compromise solution. Finally, a case study on a 5-unit system is carried out and analyzed to verify the rationality and effectiveness of the model and its solving process, and to highlight the DR ability in both reducing carbon emission and accommodating wind power.

\section{Net load curve forecasting considering WG}

WG helps realize low-carbon electricity, since it let out no $\mathrm{CO}_{2}$ into the atmosphere. However, WG output is usually uncertain, mainly depending on the wind profile. Thus power system is faced with new challenges in scheduling. Among all the probabilities of WG output, there is an extreme case that the WG output owns antipeaking characteristic. According to an actual wind farm in

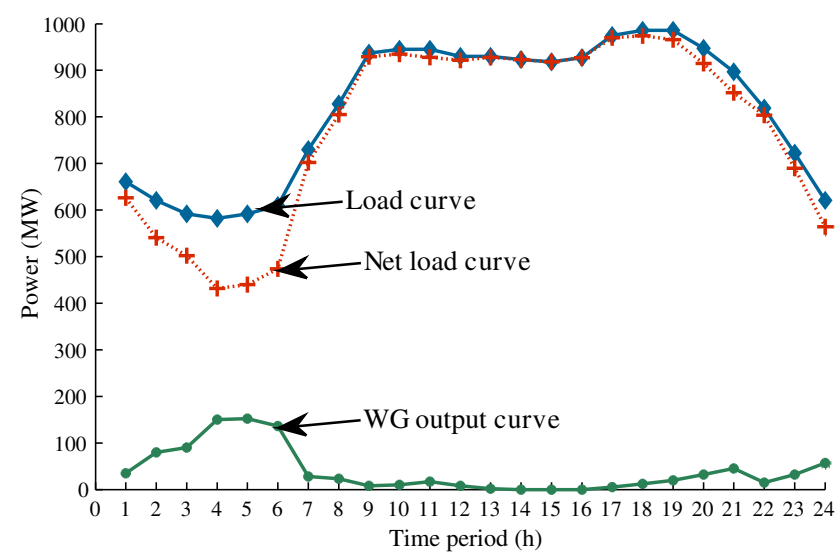

Fig. 1 Day-ahead load and wind power forecasting

China, the typical daily wind power output with antipeaking characteristic can be depicted as shown in Fig. 1. And the original load curve of the power system can be forecasted as shown in Fig. 1, with peak load on the daytime and valley load before dawn. It is obvious that antipeaking WG output presents quite different features compared with the original load curve: on the daytime, the output is weak, while during the night, it turns out to be strong.

Figure 1 considers a wind farm integrated system with the load curve and the forecasting wind power output curve. We need to ensure the priority of WG to make the best use of the wind energy, especially in its anti-peaking cases. The wind power output can be seen as a kind of load with negative value. Then we can forecast an equivalent net load curve by superimposing these two curves together, as the dotted line shown in Fig. 1. The calculation formula of net load value is expressed as:

$P_{\mathrm{LN} t}=P_{\mathrm{L} t}-P_{\mathrm{WG} t}$

where $P_{\mathrm{LN} t}, P_{\mathrm{L} t}, P_{\mathrm{WG} t}$ are the net load, original load and wind power output in $t^{\text {th }}$ hour, respectively.

As we can see from Fig. 1, the daily wind power output will aggravate the peak-valley difference of the original load curve. WG is prior to be dispatched, so thermal power units are the ones who make adjustments during the scheduling. They cooperate to make sure to generate the needed power and track the net load curve. At the load valley time, thermal power units need to reduce their output to meet the valley load demand, or even break the lower limit of generation in extreme cases, which may cause the system failure.

In this paper, DR is introduced to power system integrated with wind farms to help accommodate wind power, to deal with the peak-valley difference and to achieve a better low-carbon goal. 


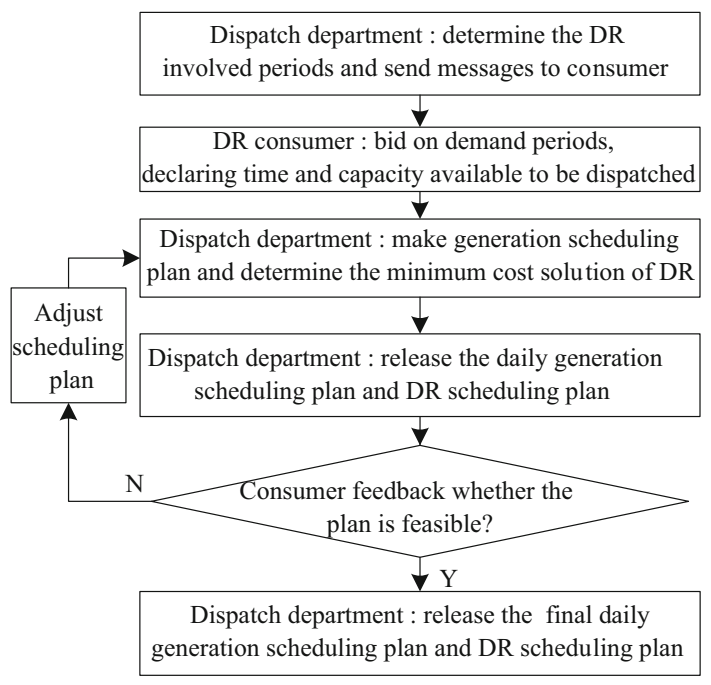

Fig. 2 Process of considering demand side interaction

\section{DR model in scheduling plan}

Generalized DR refers that users change their original habits of using electricity according to the dynamic power price or the incentive strategies. So far, DR mainly includes price-based DR and incentive-based DR. In this paper, it assumes that incentive-based DR resources interact with the dispatch department, and the process of day-ahead scheduling plan considering demand side interaction can be described as shown in Fig. 2.

During the valley period, calling on the incentive-based DR means increasing the load demand. Conversely, it could have the same effect as reducing load demand when the load summits. So DR can be considered as a generator in power system, with positive value during the peak period and negative value in the valley time.

To ensure the benefits of both generation and demand side, incentive-based DR is dispatched when the load drops below (or exceeds) a certain percentage of daily valleyload (or peak-load). As shown in (2), $\lambda_{t}$ represents DR interaction state in the $t^{\text {th }}$ period. 1 represents that there is incentive-based DR under dispatch, else $\lambda_{t}=0$.

$\lambda_{t}= \begin{cases}1 & P_{\mathrm{LN} t} \geq \varepsilon_{1} P_{\mathrm{LNmax}} \text { or } P_{\mathrm{LN} t} \leq \varepsilon_{2} P_{\mathrm{LNmin}} \\ 0 & \text { else }\end{cases}$

where $P_{\mathrm{LNmax}}$ and $P_{\mathrm{LNmin}}$ are the maximum and minimum values of net load, respectively; and $\varepsilon_{1}$ and $\varepsilon_{2}$ are the proportional coefficients of load, which are generally determined by the dispatching department.

This paper focuses on the multi-objective optimal scheduling model of a wind power integrated system considering DR and carbon emission. Mathematical formulation of the model and its solution procedure are expounded as follows.

\section{Day-ahead Pareto optimal scheduling model considering economic and low-carbon}

\subsection{Objectives}

The multi-objective optimization model is used to optimize generating cost and carbon emission.

1) Minimize generating cost

There exist three sources of generating cost needed to be considered: cost from thermal power unit, WG and DR. Based on the rules of priority for WG and the net load curve forecasting, we assume that the WG output has been decided in advance. So the cost of WG is not taken into account. Then the objective function can be described as:

$\min C=\min \left(C_{\mathrm{G}}+C_{\mathrm{DR}}\right)$

where $C_{\mathrm{G}}$ is the generating cost of thermal power units and $C_{\mathrm{DR}}$ refers to that of $\mathrm{DR}$ which includes cost for dispatching and capacity. Thus $C_{\mathrm{G}}$ and $C_{\mathrm{DR}}$ can be expressed as:

$C_{\mathrm{G}}=\sum_{t=1}^{T} \sum_{i=1}^{N_{\mathrm{g}}}\left[\left(a_{i} P_{i, t}^{2}+b_{i} P_{i, t}+c_{i}\right) I_{i, t}+S_{i, t}+D_{i, t}\right]$

$C_{\mathrm{DR}}=\sum_{t=1}^{T} \sum_{d=1}^{N_{\mathrm{DR}}}\left(c_{d} \lambda_{d, t}\left|P_{\mathrm{DR} d, t}\right|+C_{\mathrm{DR} 0}\right)$

where $T$ is a scheduling period; $N_{\mathrm{g}}$ and $N_{\mathrm{DR}}$ are the numbers of generators and DR sources, respectively; $P_{i, t}$ and $P_{\mathrm{DR} d, t}$ are the corresponding powers of thermal power unit $i$ and DR unit $d$ during the period $t$, respectively; $I_{i, t}$ and $\lambda_{d, t}$ are switching between 1 and 0 , which are the on and off operation statuses of generators and in and out calling schedules of DR, respectively; $a_{i}, b_{i}, c_{i}$ are coefficients, with the proper design of which, generating cost of units can be obtained; $c_{d}$ is a fixed coefficient of DR cost; $S_{i, t}$ and $D_{i, t}$ are the on-off operation costs; and $C_{\mathrm{DR} 0}$ is the DR capacity cost, which varies with DR capacity and is previously decided according to the commitment between the dispatch department and users.

2) Minimize carbon emission

Considering the wind power and DR as resources without emission, the thermal power unit is the only source of carbon oxides and the objective function can be constructed as below:

$\min E=\min \sum_{t=1}^{T} \sum_{i=1}^{N_{\mathrm{g}}}\left[\left(\alpha_{i} P_{i, t}^{2}+\beta_{i} P_{i, t}+\gamma_{i}\right) I_{i, t}\right]$

where $\alpha_{i}, \beta_{i}, \gamma_{i}$ are the coefficients of carbon emission.

\subsection{Constraint conditions}

The power balance constraint is expressed as follows: 
$\sum_{i=1}^{N_{\mathrm{g}}} P_{i, t} I_{i, t}=P_{\mathrm{LN} t}-\sum_{d=1}^{N_{\mathrm{DR}}} \lambda_{d, t} P_{\mathrm{DR} d, t}$

where $P_{\mathrm{LN} t}$ is the system net load during the period $t$ and $P_{\mathrm{DR} d, t}$ is the reduction amount of DR unit $d$.

Spinning reserve is essential to support the security of the power system. To economize the generating cost of thermal power units, DR units also can be adopted to work as reserve. The reserve constraints of this power system can be written as below:

$\sum_{i=1}^{N_{\mathrm{g}}} I_{i, t}\left(P_{i \max }-P_{i, t}\right)+\sum_{d=1}^{N_{\mathrm{DR}}} \lambda_{d, t}\left(\left|P_{\mathrm{DR} d \max }\right|-\left|P_{\mathrm{DR} d, t}\right|\right) \geq \mu P_{\mathrm{LN} t}$

where $P_{i \max }$ is the maximum output of generation unit $i$; the hot spare coefficient $\mu$ is denoted as $10 \%$; and $P_{\mathrm{DR} d \max }$ is the maximum power injection of DR unit $d$.

Generator power constraint is given in the following inequality:

$P_{i \max } \geq P_{i, t} I_{i, t} \geq P_{i \min }$

where $P_{i \min }$ is the minimum output of generation units.

The ramp constraint of generating sets is shown as below:

$R U_{i} \geq P_{i, t}-P_{i,(t-1)} \geq-R D_{i}$

where $R D_{i}$ and $R U_{i}$ are ramp-up and ramp-down limits of unit $i$, respectively.

The generators on-off time constraints are written in (11) and (12).

$$
\begin{aligned}
& \left(I_{i,(t-1)}-I_{i, t}\right)\left(t_{i,(t-1)}^{\mathrm{on}}-T_{i \min }^{\mathrm{on}}\right) \geq 0 \\
& \left(I_{i, t}-I_{i,(t-1)}\right)\left(t_{i,(t-1)}^{\mathrm{off}}-T_{i \min }^{\mathrm{off}}\right) \geq 0
\end{aligned}
$$

where $t_{i,(t-1)}^{\text {on }}$ and $t_{i,(t-1)}^{\text {off }}$ are start-up and shut-down times of unit $i$ during the period $t-1$, respectively; and $T_{i \min }^{\text {on }}$ and $T_{i \min }^{\text {off }}$ are the minimum up and down times of unit $i$, respectively.

DR should be scheduled within its capacity limit

$$
\left|P_{\mathrm{DR} d \max }\right| \geq \lambda_{d, t}\left|P_{\mathrm{DR} d, t}\right| \geq 0
$$

where $P_{\mathrm{DR} d \max }$ is the upper capacity limit of DR $d$.

\section{Solution of multi-objective model}

\subsection{Flow of model solving}

NSGA-II is adopted [26, 27] to solve the proposed model, mainly including determining the unit commitment and load distribution scheme in each period. The flow of model solving is shown in Fig. 3.

\subsection{Optimal Pareto sets and decision-making model}

\section{1) Optimal Pareto sets}

NSGA-II is one of the advanced algorithms most widely used in multi-objective optimization. NSGA-II can provide Pareto sets through non-dominated sorting techniques and crowding distance operator. In this paper, thermal power unit output $\left(P_{i, t}\right)$ and DR dispatch amount $\left(P_{\mathrm{DR} d, t}\right)$ are taken as decision variables in the solving flow. By calculating the generating cost and carbon emission, set of non-dominated solutions is obtained. Every non-dominated solution refers to a UC scheme. In the multi-objective optimal problem, a single objective usually contradicts others. So the Pareto front contains a wealth of information and can provide decision makers with whatever they prefer to choose.

2) Decision-making model

Among all the non-dominated solutions, the satisfactionmaximizing method is taken to choose an eclectic decision in this paper. And the processes include two steps as follows.

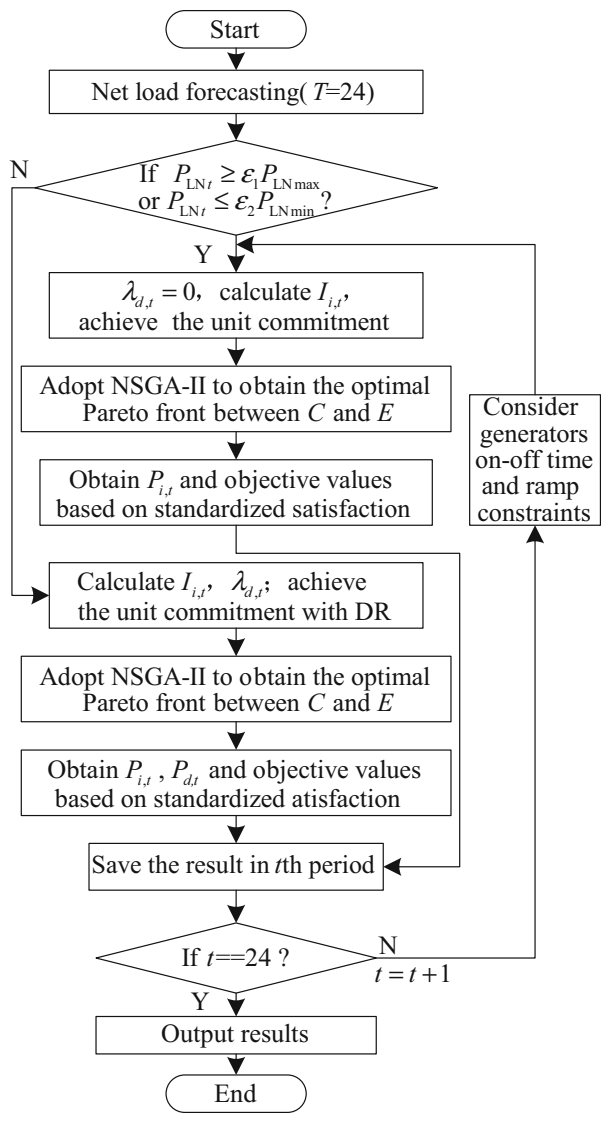

Fig. 3 Flow chart of model solving 
Table 1 Parameters of thermal power units

\begin{tabular}{|c|c|c|c|c|c|c|c|c|c|c|c|c|c|c|}
\hline Generator & $\begin{array}{l}a_{i} \\
\left(\$ \cdot(\mathrm{MWh})^{-2}\right)\end{array}$ & $\begin{array}{l}b_{i} \\
\left(\$ \cdot(\mathrm{MWh})^{-1}\right)\end{array}$ & $\begin{array}{l}c_{i} \\
(\$)\end{array}$ & $\begin{array}{l}\alpha_{i} \\
\left(\mathrm{t} \cdot(\mathrm{MWh})^{-2}\right)\end{array}$ & $\begin{array}{l}\beta_{i} \\
\left(\mathrm{t} \cdot(\mathrm{MWh})^{-1}\right)\end{array}$ & $\gamma_{i}(\mathrm{t})$ & $\begin{array}{l}R U_{i} \\
(\mathrm{MW})\end{array}$ & $\begin{array}{l}R D_{i} \\
(\mathrm{MW})\end{array}$ & $\begin{array}{l}T_{i \min }^{\text {on }} \\
(\mathrm{t})\end{array}$ & $\begin{array}{l}T_{i \min }^{\text {off }} \\
\text { (t) }\end{array}$ & $\begin{array}{l}S_{i} \\
(\$)\end{array}$ & $\begin{array}{l}D_{i} \\
(\$)\end{array}$ & $\begin{array}{l}P_{i \max } \\
(\mathrm{MW})\end{array}$ & $\begin{array}{l}P_{i \min } \\
(\mathrm{MW})\end{array}$ \\
\hline 1 & 0.0492 & 29.64 & 2964 & $6.752 \times 10^{-6}$ & $-5.776 \times 10^{-6}$ & $4.256 \times 10^{-6}$ & 50 & 50 & 2 & 2 & 172 & 50 & 200 & 80 \\
\hline 2 & 0.0636 & 55.08 & 1272 & $5.864 \times 10^{-6}$ & $-6.663 \times 10^{-6}$ & $2.645 \times 10^{-6}$ & 30 & 30 & 2 & 2 & 145 & 30 & 100 & 40 \\
\hline 3 & 0.0508 & 50.84 & 2120 & $4.769 \times 10^{-6}$ & $-5.298 \times 10^{-6}$ & $4.428 \times 10^{-6}$ & 160 & 160 & 2 & 2 & 267 & 85 & 600 & 240 \\
\hline 4 & 0.0636 & 55.08 & 1272 & $3.515 \times 10^{-6}$ & $-3.692 \times 10^{-6}$ & $5.539 \times 10^{-6}$ & 60 & 60 & 2 & 2 & 180 & 52 & 300 & 100 \\
\hline 5 & 0.0508 & 50.84 & 2120 & $4.769 \times 10^{-6}$ & $-5.298 \times 10^{-6}$ & $4.428 \times 10^{-6}$ & 60 & 60 & 2 & 2 & 187 & 60 & 300 & 100 \\
\hline
\end{tabular}

Step 1: calculate satisfaction value of non-dominated solution corresponding objective function by using the fuzzy-satisfaction function. To minimize the objectives of total generation cost considering DR compensation fees and carbon emission, lower semi linear is selected for satisfaction function. Two satisfaction functions of the objective functions are shown in (14) and (15).

$$
\begin{aligned}
& u_{1}^{k}=\left\{\begin{array}{lc}
1 & C_{k} \leq C_{\min } \\
1-\frac{C_{k}-C_{\max }}{C_{\max }-C_{\min }} C_{\min }<C_{k}<C_{\max } \\
0 & C_{k} \geq C_{\max }
\end{array}\right. \\
& u_{2}^{k}= \begin{cases}1 & E_{k} \leq E_{\min } \\
1-\frac{E_{k}-E_{\min }}{E_{\min }-E_{\max }} & E_{\min }<E_{k}<E_{\max } \\
0 & E_{k} \geq E_{\max }\end{cases}
\end{aligned}
$$

where $u_{1}^{k}$ and $C_{k}$ are the satisfaction and target values of objective function 1 in corresponding non-dominated solution $k$, respectively; $u_{2}^{k}$ and $E_{k}$ are the satisfaction and target values of objective function 2 in corresponding nondominated solution $k$, respectively.

Step 2: based on the satisfaction value obtained in step 1 and constraint (16), calculate the standard satisfaction value of each non-dominated solution. The maximum nondominated solution of standard satisfaction is the optimum eclectic solution.

$u^{k}=\sum_{m=1}^{M} u_{m}^{k} / \sum_{k=1}^{N} \sum_{m=1}^{M} u_{m}^{k}$

where $u^{k}$ is the standardization of satisfaction corresponding non-dominated solution $k ; M$ is the number of objective function; and $N$ is the number of non-dominated solutions.

\section{Case study}

Here a case study on a system with five thermal power units and a wind farm is conducted, assuming that there exist three DR resources participating in the bidding. Make sure that WG is prior to be dispatched, and the day-ahead net load curve of the whole power system is as the dotted
Table 2 Parameters of DR resources

\begin{tabular}{llll}
\hline $\mathrm{DR}$ & $\left|P_{\mathrm{DR} d \max }\right|(\mathrm{MW})$ & $c_{d}\left(\$ \cdot \mathrm{MW}^{-1}\right)$ & $C_{\mathrm{DR} 0}(\$)$ \\
\hline $\mathrm{DR} 1$ & 40 & 5 & 200 \\
$\mathrm{DR} 2$ & 40 & 5.5 & 200 \\
DR3 & 60 & 36 & 300 \\
\hline
\end{tabular}

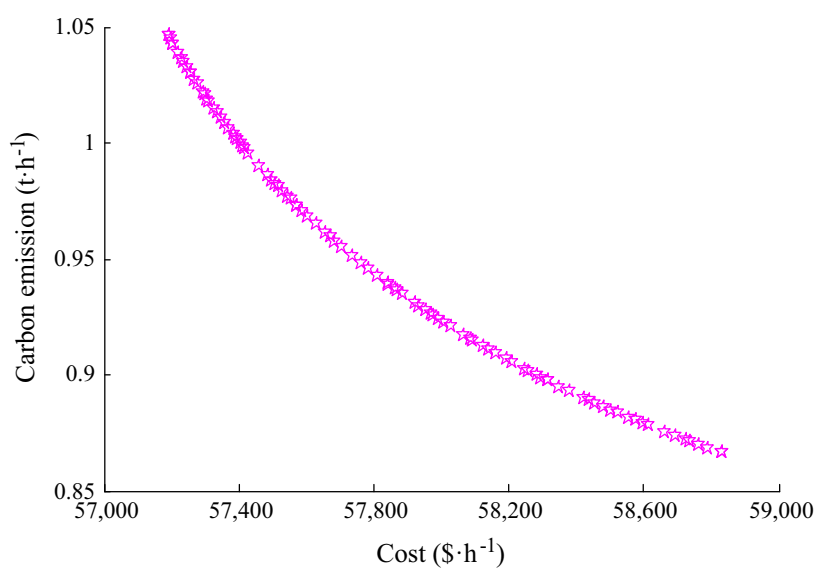

Fig. 4 Optimal Pareto front in case 1

line shown in Fig. 1. The parameters of thermal power units and DR are shown in Table 1 and Table 2, respectively. Scheduling period is assumed to be one day, and simplified into 24 periods.

To stress the significance and effect of DR, a comparative study on two different cases is preceded. Case 1: double-objective model without DR. Case 2: doubleobjective model with DR. Two cases are both solved with NSGA-II in MATLAB. In the process of solving, the generation is set with 1000. Among all the Pareto fronts obtained when solving the model, two typical optimal Pareto fronts are shown in Fig. 4 and Fig. 5. The standard satisfaction is used to select the optimal compromise solution from the non-dominated solution set.

In Pareto fronts, a single dot represents a non-dominated solution. The solution sets are diverse and uniformly distributed, which prove the excellent searching ability and robustness of the solving process based on NSGA-II. As we can see from Fig. 4 and Fig. 5, all the non-dominated solutions make up a line showing that the 
two objectives are inversely proportional. Take Fig. 4 as an example: to reduce carbon emission from $1.05 \mathrm{t}$ to $0.87 \mathrm{t}$, the cost should be increased by $1,600 \$$. Reducing carbon emission will absolutely cause the increase of total cost. If we pursue economic aim only,

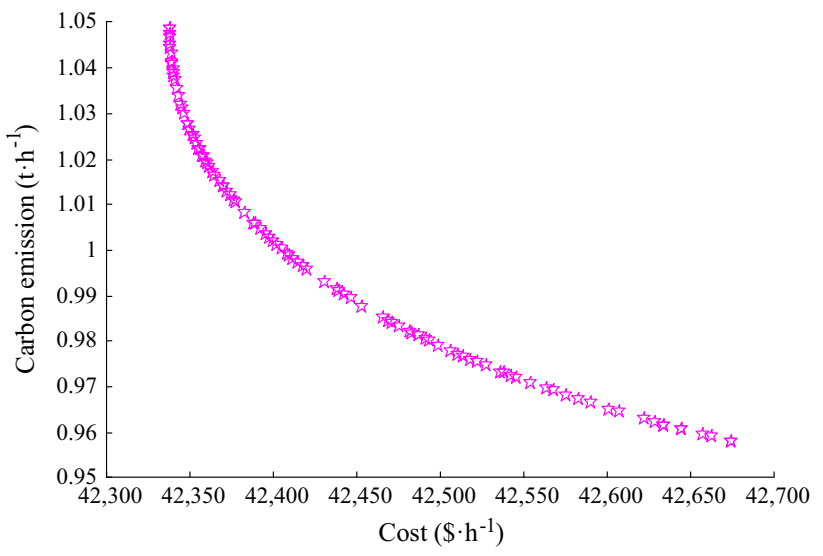

Fig. 5 Optimal Pareto front in case 2 the cost can be reduced to $57,200 \$$, with $1.05 \mathrm{t} \mathrm{CO}_{2}$ emission. So the environmental goal often goes against the economic aim. Pareto fronts contain a wealth of information, providing a set of solutions of good quality for the decision makers to choose according to their preferences.

The maximum and minimum objective values and the corresponding standard satisfaction-maximizing in solving the double-objective optimal model are shown in Table 3. The optimal compromise solutions of UC of case 1 and case 2 are shown in Fig. 6 and Fig. 7.

Figure 6 shows that without DR, the output of unit 3 is close to its maximum limit, the unit output maximum peakvalley difference is $260 \mathrm{MW}$. In Fig. 7, the proposed model can invoke DR effectively in both peak and valley load period, thus the unit output maximum peak-valley difference is reduced to $228 \mathrm{MW}, 32 \mathrm{MW}$ less than case 1.

The analysis data from Fig. 7 and Table 4 reflects that the optimal dispatching scheme considering DR is more satisfied to the dispatching center in Power Company. Calling DR in both peak and valley periods can ensure

Table 3 Maximum and minimum objective values of multi-objective and standard satisfaction-maximizing

\begin{tabular}{|c|c|c|c|c|c|c|c|c|c|c|}
\hline \multirow[t]{2}{*}{ Time period } & \multicolumn{5}{|l|}{ Case 1} & \multicolumn{5}{|l|}{ Case 2} \\
\hline & $C_{\max }(\$)$ & $C_{\min }(\$)$ & $E_{\max }(\mathrm{t})$ & $E_{\min }(\mathrm{t})$ & $u$ & $C_{\max }(\$)$ & $C_{\min }(\$)$ & $E_{\max }(\mathrm{t})$ & $E_{\min }(\mathrm{t})$ & $u$ \\
\hline 1 & $47.02 \times 10^{3}$ & $38.08 \times 10^{3}$ & 1.21 & 0.49 & 0.006 & $50.87 \times 10^{3}$ & $41.58 \times 10^{3}$ & 1.21 & 0.48 & 0.005 \\
\hline 2 & $34.87 \times 10^{3}$ & $34.69 \times 10^{3}$ & 0.44 & 0.42 & 0.021 & $38.36 \times 10^{3}$ & $38.20 \times 10^{3}$ & 0.43 & 0.42 & 0.030 \\
\hline 3 & $31.78 \times 10^{3}$ & $21.13 \times 10^{3}$ & 0.68 & 0.24 & 0.006 & $35.62 \times 10^{3}$ & $24.37 \times 10^{3}$ & 0.66 & 0.24 & 0.007 \\
\hline 4 & $25.29 \times 10^{3}$ & $24.90 \times 10^{3}$ & 0.58 & 0.52 & 0.032 & $34.27 \times 10^{3}$ & $32.27 \times 10^{3}$ & 0.66 & 0.46 & 0.011 \\
\hline 5 & $24.17 \times 10^{3}$ & $19.91 \times 10^{3}$ & 0.61 & 0.18 & 0.010 & $31.97 \times 10^{3}$ & $25.22 \times 10^{3}$ & 0.66 & 0.17 & 0.008 \\
\hline 6 & $26.43 \times 10^{3}$ & $26.30 \times 10^{3}$ & 0.59 & 0.54 & 0.030 & $33.40 \times 10^{3}$ & $33.20 \times 10^{3}$ & 0.48 & 0.43 & 0.030 \\
\hline 7 & $47.87 \times 10^{3}$ & $44.94 \times 10^{3}$ & 1.22 & 0.87 & 0.018 & $50.29 \times 10^{3}$ & $45.91 \times 10^{3}$ & 1.00 & 0.72 & 0.018 \\
\hline 8 & $52.62 \times 10^{3}$ & $52.34 \times 10^{3}$ & 0.95 & 0.92 & 0.024 & $55.41 \times 10^{3}$ & $54.85 \times 10^{3}$ & 0.97 & 0.89 & 0.031 \\
\hline 9 & $63.66 \times 10^{3}$ & $50.01 \times 10^{3}$ & 1.09 & 1.00 & 0.019 & $56.11 \times 10^{3}$ & $50.28 \times 10^{3}$ & 1.07 & 0.76 & 0.019 \\
\hline 10 & $54.88 \times 10^{3}$ & $54.65 \times 10^{3}$ & 1.22 & 1.12 & 0.028 & $56.33 \times 10^{3}$ & $55.37 \times 10^{3}$ & 0.90 & 0.79 & 0.027 \\
\hline 11 & $62.57 \times 10^{3}$ & $50.55 \times 10^{3}$ & 1.42 & 1.18 & 0.018 & $63.92 \times 10^{3}$ & $50.62 \times 10^{3}$ & 1.21 & 0.82 & 0.017 \\
\hline 12 & $54.33 \times 10^{3}$ & $54.08 \times 10^{3}$ & 1.28 & 1.17 & 0.028 & $55.21 \times 10^{3}$ & $54.65 \times 10^{3}$ & 1.04 & 0.92 & 0.030 \\
\hline 13 & $63.40 \times 10^{3}$ & $49.94 \times 10^{3}$ & 1.40 & 1.20 & 0.024 & $62.36 \times 10^{3}$ & $48.63 \times 10^{3}$ & 1.05 & 0.91 & 0.028 \\
\hline 14 & $59.54 \times 10^{3}$ & $58.89 \times 10^{3}$ & 1.23 & 1.07 & 0.030 & $59.19 \times 10^{3}$ & $58.42 \times 10^{3}$ & 1.01 & 0.88 & 0.030 \\
\hline 15 & $64.00 \times 10^{3}$ & $43.54 \times 10^{3}$ & 1.17 & 0.97 & 0.015 & $63.73 \times 10^{3}$ & $50.25 \times 10^{3}$ & 1.16 & 0.75 & 0.018 \\
\hline 16 & $54.96 \times 10^{3}$ & $54.47 \times 10^{3}$ & 1.20 & 1.07 & 0.031 & $55.65 \times 10^{3}$ & $54.57 \times 10^{3}$ & 0.83 & 0.71 & 0.027 \\
\hline 17 & $65.74 \times 10^{3}$ & $53.77 \times 10^{3}$ & 1.70 & 1.28 & 0.020 & $66.98 \times 10^{3}$ & $53.71 \times 10^{3}$ & 1.29 & 0.90 & 0.016 \\
\hline 18 & $58.07 \times 10^{3}$ & $57.98 \times 10^{3}$ & 1.47 & 1.38 & 0.032 & $57.90 \times 10^{3}$ & $57.58 \times 10^{3}$ & 1.10 & 1.03 & 0.027 \\
\hline 19 & $66.16 \times 10^{3}$ & $52.61 \times 10^{3}$ & 1.56 & 1.36 & 0.019 & $64.63 \times 10^{3}$ & $50.30 \times 10^{3}$ & 1.16 & 1.02 & 0.026 \\
\hline 20 & $59.00 \times 10^{3}$ & $58.44 \times 10^{3}$ & 1.14 & 1.04 & 0.026 & $58.66 \times 10^{3}$ & $57.79 \times 10^{3}$ & 0.96 & 0.85 & 0.030 \\
\hline 21 & $59.57 \times 10^{3}$ & $38.12 \times 10^{3}$ & 1.07 & 0.80 & 0.010 & $62.66 \times 10^{3}$ & $42.50 \times 10^{3}$ & 1.13 & 0.78 & 0.012 \\
\hline 22 & $41.00 \times 10^{3}$ & $40.73 \times 10^{3}$ & 0.83 & 0.81 & 0.030 & $46.07 \times 10^{3}$ & $45.21 \times 10^{3}$ & 0.85 & 0.77 & 0.024 \\
\hline 23 & $34.04 \times 10^{3}$ & $28.29 \times 10^{3}$ & 0.82 & 0.54 & 0.008 & $38.85 \times 10^{3}$ & $33.28 \times 10^{3}$ & 0.87 & 0.59 & 0.007 \\
\hline 24 & $28.04 \times 10^{3}$ & $27.84 \times 10^{3}$ & 0.41 & 0.39 & 0.017 & $32.57 \times 10^{3}$ & $32.42 \times 10^{3}$ & 0.45 & 0.42 & 0.030 \\
\hline
\end{tabular}




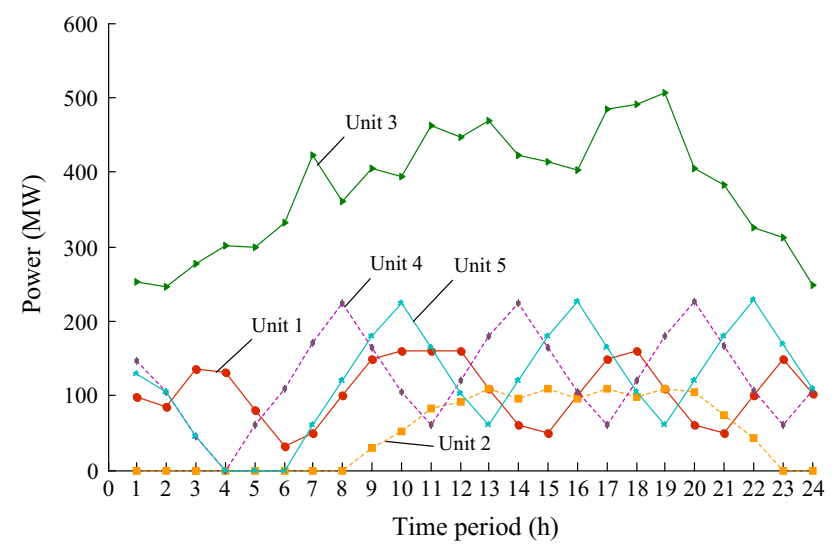

Fig. 6 Thermal unit output of case 1 based on standardized satisfaction decision

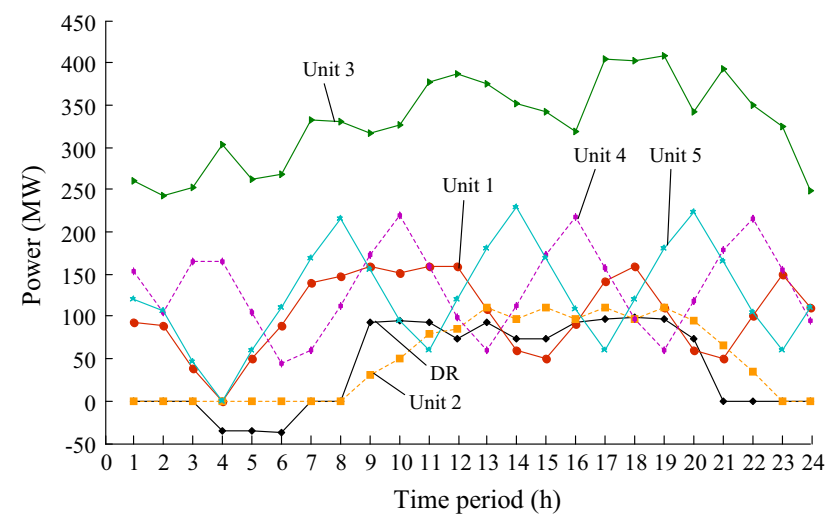

Fig. 7 Thermal unit output and DR of case 2 based on standardized satisfaction decision

the regulating ability of power system to accommodate the wind power. As is shown in Fig. 7, during the valley time, dispatching DR refers to encouraging users to use more power, which would help accommodate the antipeaking wind power; while in the peak time, DR works as generation for the system, to reduce part of the interruptible load to ensure the stability of the thermal power unit. The maximum adjustment power value of DR in single scheduling period is $50 \mathrm{MW}$, accounted for $10 \%$ of the load in the period. Others are between $7 \%-10 \%$. Table 5 shows the carbon emission difference of different schemes. When there are no DR units dispatched, the carbon emission is essentially unchanged. Otherwise, the carbon emission will decrease if DR units are put into compensation.

Table 6 shows the minimum generating costs and carbon emission of case 1 and case 2 with the maximum satisfaction strategy. It can be seen from Table 6 that, when the DR units inject power into the grid, the whole generating cost of coal-fired units is decreased by 5,280 $\$$, with energy consumption and on-off cost of generators considered. With DR participation, in the peak load period, part of the load is reduced for reinforcing the hot spares of power system and the DR compensation cost is increased by $16,675.5 \$$ which is merely $1.5 \%$ of the whole cost. As a result, it makes the total generating cost increased by $13,820.4 \$$. In the valley period, DR helps to increase the load demand to accommodate the wind power and maintain the stability of the system. As for carbon emission, when DR units are dispatched, the carbon emission is decreased by $4.13 \mathrm{t}$, which means the good environmental benefit. In summary, the proposed scheduling model can achieve $19 \%$ reduction in carbon emission by merely increasing $1.3 \%$ of power generation cost. Thus, in case of which, carbon emission reduction is an absolute target, and the model proposed can effectively utilize the DR to reduce carbon emission.

Table 4 Optimal scheme of DR

\begin{tabular}{|c|c|c|c|c|c|c|c|}
\hline Time period & $P_{\mathrm{DR} 1}(\mathrm{MW})$ & $P_{\mathrm{DR} 2}(\mathrm{MW})$ & $P_{\mathrm{DR} 3}(\mathrm{MW})$ & Time period & $P_{\mathrm{DR} 1}(\mathrm{MW})$ & $P_{\mathrm{DR} 2}(\mathrm{MW})$ & $P_{\mathrm{DR} 3}(\mathrm{MW})$ \\
\hline 1 & 0 & 0 & 0 & 13 & 39.5 & 40 & 13.5 \\
\hline 2 & 0 & 0 & 0 & 14 & 36.8 & 37.2 & 0 \\
\hline 3 & 0 & 0 & 0 & 15 & 37 & 37 & 0 \\
\hline 4 & -35 & 0 & 0 & 16 & 40 & 39.4 & 13.6 \\
\hline 5 & -29.5 & -0.1 & -6.3 & 17 & 39.8 & 40 & 17.2 \\
\hline 6 & -38 & 0 & 0 & 18 & 40 & 39.2 & 18.8 \\
\hline 7 & 0 & 0 & 0 & 19 & 40 & 40 & 17 \\
\hline 8 & 0 & 0 & 0 & 20 & 36.2 & 37.8 & 0 \\
\hline 9 & 40 & 40 & 13 & 21 & 0 & 0 & 0 \\
\hline 10 & 40 & 38.2 & 15.8 & 22 & 0 & 0 & 0 \\
\hline 11 & 40 & 40 & 13 & 23 & 0 & 0 & 0 \\
\hline 12 & 38.6 & 35.4 & 0 & 24 & 0 & 0 & 0 \\
\hline
\end{tabular}


Table 5 Comparison results of carbon emission with/without DR

\begin{tabular}{|c|c|c|c|c|c|c|c|}
\hline Time period & Without DR (t) & With DR (t) & Difference value (t) & Time period & Without DR (t) & With DR (t) & Difference value $(t)$ \\
\hline 1 & 0.52 & 0.53 & -0.01 & 13 & 1.15 & 0.93 & 0.21 \\
\hline 2 & 0.43 & 0.42 & 0 & 14 & 1.05 & 0.75 & 0.3 \\
\hline 3 & 0.49 & 0.4 & 0.09 & 15 & 1.13 & 0.76 & 0.37 \\
\hline 4 & 0.54 & 0.53 & 0.02 & 16 & 1.35 & 1 & 0.35 \\
\hline 5 & 0.44 & 0.36 & 0.08 & 17 & 1.42 & 1.06 & 0.36 \\
\hline 6 & 0.57 & 0.45 & 0.11 & 18 & 1.42 & 1.03 & 0.39 \\
\hline 7 & 0.98 & 0.81 & 0.18 & 19 & 1.09 & 0.9 & 0.19 \\
\hline 8 & 0.93 & 0.93 & 0.01 & 20 & 0.86 & 0.86 & 0 \\
\hline 9 & 1.09 & 0.76 & 0.33 & 21 & 0.82 & 0.81 & 0.01 \\
\hline 10 & 1.17 & 0.84 & 0.33 & 22 & 0.62 & 0.67 & -0.04 \\
\hline 11 & 1.24 & 0.9 & 0.34 & 23 & 0.4 & 0.43 & -0.03 \\
\hline 12 & 1.22 & 0.99 & 0.23 & 24 & 1.15 & 0.93 & 0.21 \\
\hline
\end{tabular}

Table 6 Results comparison under different cases

\begin{tabular}{lllccc}
\hline Case & Energy consumption (\$) & On-off cost (\$) & DR compensation cost (\$) & Total cost (\$) & Carbon emission $(\mathrm{t})$ \\
\hline Without DR (Case 1) & $1,068,437$ & 2,432 & 0 & $1,068,437$ & 22.16 \\
With DR (Case 2) & $1,063,156$ & 2,252 & $16,675.5$ & $1,082,084$ & 18.03 \\
\hline
\end{tabular}

\section{Conclusion}

This paper proposes an economic and low-carbon dayahead Pareto optimal scheduling plan for wind farm integrated power systems with DR. By introducing DR into traditional UC strategy, the model can help alleviate the working pressure of coal-fired thermal power units in both peak and valley load period, reduce carbon emission and energy consumption of generation units, and accommodate the wind power. The NSGA-II-based algorithm provides Pareto fronts with a wealth of solutions for decision makers. And the optimal solution is obtained with consideration of the maximum satisfaction in each period. The scheduling model proposed can well meet the national need to reduce carbon emission. Uncertainty of WG is still needed to be carefully considered in the future research.

Acknowledgment This work is supported by National Natural Science Foundation of China (No. 51277015).

Open Access This article is distributed under the terms of the Creative Commons Attribution License which permits any use, distribution, and reproduction in any medium, provided the original author(s) and the source are credited.

\section{References}

[1] Kang CQ, Chen QX, Xia Q (2009) Prospects of low-carbon electricity. Power Syst Technol 32(2):1-7
[2] Chen QX, Kang CQ, Ge J et al (2009) Analysis on reduction model of $\mathrm{CO}_{2}$ emission in power sector based on emission trajectory model. Power Syst Technol 33(19):44-49

[3] Li CB, Liu Y, Cao YJ et al (2011) Consistency evaluation of low-carbon generation dispatching and energy-saving generation dispatching. Proc CSEE 31(31):94-101

[4] Chen QX, Zhou TR, Kang CQ et al (2009) An assessment model of low- carbon effect and its application to energy saving based generation dispatching. Automat Electr Power Syst 33(16):24-29

[5] Ma R (2002) A novel bi-objective fuzzy optimal model of short-term trade planning considering environmental protection and economic profit in deregulated power system. Proc CSEE 22(4):104-106

[6] Zhang XH, Zhao JQ, Chen XY (2010) Multi-objective unit commitment fuzzy modeling and optimization for energy-saving and emission reduction. Proc CESS 30(22):71-76

[7] Zhu YS, Wang J, Qu BY et al (2014) Environmental economic dispatch adopting multi-objective evolutionary algorithm based on decomposition. Power Syst Technol 38(6):1577-1584

[8] Chen QX, Kang CQ, Xia Q (2010) Mechanism and modeling approach to low-carbon power dispatch. Automat Electr Power Syst 34(12):18-23

[9] Xiong N, Wu Y, Cai H et al (2013) Low carbon generation dispatch considering static voltage stability. Proc CSEE 33(4):62-67

[10] Chen Z (2013) Wind power in modern power systems. J Modern Power Syst Clean Energ 1(1):2-13

[11] Zhang XH, Dong XH (2013) Research on multi-objective scheduling for low-carbon power system with wind farms. Power Syst Technol 37(1):24-31

[12] Chen DJ, Gong QW, Zhang ML et al (2011) Multi-objective optimal dispatch in wind power integrated system incorporating energy-environmental efficiency. Proc CSEE 31(13):10-17

[13] Wang BB, Liu XC, Li Y (2013) Day-ahead generation scheduling and operation simulation considering demand response in large-capacity wind power integrated systems. Proc CSEE 33(22):35-44 
[14] Zhu LZ, Chen N, Han HL (2011) Key problems and solutions of wind power accommodation. Automat Electr Power Syst 35(22): 29-34

[15] US Department of Energy (2006) Benefits of demand response in electricity markets and recommendations for achieving them. In: a report to the United States congress pursuant to section 1252 of the energy policy act of 2005. US Department of Energy, Washington, DC

[16] Federal Energy Regulatory Commission (2009) A national assessment of demand response potential: Staff report. Federal Energy Regulatory Commission, US Department of Energy, Washington, DC

[17] Zhang Q, Wang XF, Wang JX et al (2008) Survey of demand research in deregulated electricity markets. Automat Electr Power Syst 32(3):97-106

[18] Wu HY, Shahidehpour M, Al-Abdulwahab A (2013) hourly demand response in day-ahead scheduling for managing the variability of renewable energy. IET Gener Transm Distrib 7(3):226-234

[19] Parvania M, Fotuhi-Firuzabad M, Shahidehpour M (2011) Assessing impact of demand response in emission-constrained environments. In: Proceedings of the 2001 IEEE power and energy society general meeting, 24-29 Jul 2011, San Diego, CA, USA, p 6

[20] Huang SK, Infield D, Cruden A et al (2013) Plug-in electric vehicles as demand response to absorb local wind generation in power distribution network. In: Proceedings of the 2013 world electric vehicle symposium and exhibition, 17-20 Nov 2013, Barcelona, Spain, p 5

[21] Xia Y, Kang CQ, Ning B et al (2012) A generation and load integrated scheduling on interaction mode on customer side. Automat Electr Power Syst 36(1):17-23

[22] Liu XC, Wang BB, Li Y et al (2013) Day-ahead generation scheduling model considering demand side interaction under smart grid paradigm. Proc CSEE 33(1):30-38

[23] Zhao CY, Wang JH, Watson JP et al (2013) Multi-stage robust unit commitment considering wind and demand response uncertainties. IEEE Trans Power Syst 28(3):2708-2717

[24] Zhang N, Hu ZG, Zhou YH et al (2014) A novel fuzzy biobjective unit commitment model considering demand side lowcarbon resources. Automat Electr Power Syst 38(17):25-30

[25] Liu X, Ai X, Peng Q et al (2012) Optimal dispatch coordinating power generation with carbon emission permit for wind farms integrated power grid considering demand response. Power Syst Technol 36(1):213-218
[26] Trivedi A, Pindoriya NM, Sprinivasan D (2010) Modified NSGA-II for day-ahead multi-objective thermal generation scheduling. In: Proceedings of the 2010 IPEC, 27-29 Oct 2010, Singapore, pp 752-757

[27] Li YF, Pedroni N, Zio E (2013) A memetic evolutionary multiobjective optimization method for environmental power unit commitment. IEEE Trans Power Syst 28(3):2660-2669

Rui MA received the B.Sc. degree in Electrical Engineering, the M.Sc. degree in Control Theory and Contol Enginnering, and the Ph.D. degree in Electrical Engineering from Changsha University of Electric Power, Hunan University and North China Electric Power University in 1994, 1999 and 2006, respectively. From September 2009 to July 2011, He was a Visiting Scholar in Texas A\&M University. Now he is a Professor in the School of Electrical and Information Engineering, Changsha University of Science and Technology. His research is in the area of power system security analysis, renewable energy accessing, electricity market and lowcarbon electricity.

Kai LI received the B.Sc. degree in Electrical Engineering from University of South China in 2011. He is currently pursuing the M.Sc. in Electrical Engineering at Changsha University of Science and Technology. His research interests include optimal dispatch in power systems and low-carbon electricity.

Xuan LI received the B.Sc. degree in Electrical Engineering from Changsha University of Science and Technology in 2014. She is now pursuing the M.Sc. degree in Electrical Engineering at Changsha University of Science and Technology. Her research interests include optimal dispatch in power systems and low-carbon electricity.

Zeyu QIN received the B.Sc. degree in Electrical Engineering from Changsha University of Science and Technology in 2013. He is now pursuing the M.Sc. degree in Electrical Engineering at Changsha University of Science and Technology. His research interests include power system security analysis and low-carbon electricity. 